\title{
PART A: AUTOMATED DESIGN ANALYSIS, ASSEMBLY PLANNING AND MOTION STUDY ANALYSIS USING IMMERSIVE VIRTUAL REALITY.
}

\author{
JAMES M. RITCHIE*, RAYMOND C.W. SUNG, GRAHAM ROBINSON, \\ PHILIP N. DAY, RICHARD G. DEWAR, JONATHAN R. CORNEY, \\ JOHN E.L. SIMMONS \\ Scottish Manufacturing Institute, Heriot-Watt University, Edinburgh, EH14 4AS, UK \\ *Corresponding author. Tel.: +44 131451 4364, fax: +44 1314513129 Email: \\ J.M.Ritchie@hw.ac.uk*, G.Robinson@hw.ac.uk,P.N.Day@hw.ac.uk, R.G.Dewar@hw.ac.uk, \\ R.C.W.Sung@hw.ac.uk,J.Simmons@hw.ac.uk
}

Abstract: $\quad$ Previous research work at Heriot-Watt University using immersive virtual reality (VR) for cable harness design showed that VR provided substantial productivity gains over traditional computer-aided design (CAD) systems. This follow-on work was aimed at understanding the degree to which aspects of this technology were contributed to these benefits and to determine if engineering design and planning processes could be analysed in detail by nonintrusively monitoring and logging engineering tasks. This involved using a CAD-equivalent VR system for cable harness routing design, harness assembly and installation planning that can be functionally evaluated using a set of creative design-tasks to measure the system and users' performance. A novel design task categorisation scheme was created and formalised which broke down the cable harness design process and associated activities. The system was also used to demonstrate the automatic generation of usable bulkhead connector, cable harness assembly and cable harness installation plans from non-intrusive user logging. Finally, the data generated from the user-logging allowed the automated activity categorisation of the user actions, automated generation of process flow diagrams and chronocyclegraphs.

Key words: Virtual reality, user logging, process flow diagrams, assembly planning, motion study, user activity categorisation 


\section{INTRODUCTION}

Virtual reality (VR) will become widely used over the next few years throughout the product design process. In the recent past immersive VR applications have been mainly used in the research laboratory and larger companies; however, as this technology becomes cost effective and more widely used in product engineering it is important to understand how to analyse its use and evaluate its benefits and limitations.

In this paper the main focus is on using head-mounted display (HMD) immersive VR as a tool for the analysis of a creative design task, namely the $3 \mathrm{D}$ generation of cable harness routes. A design task categorisation system is described and tested successfully on the design task investigated. Finally, it is proposed that this work provides the potential for formalising the design rationale of the designer which can be identified by logging the user activities and then attempting to recognize signature patterns relating to design activities.

It then specifically describes the immersive VR apparatus and experimental methodology used to investigate cable harnesses design followed by a detailed analysis and discussion of results. This is followed by a section demonstrating the potential for automatically generating manufacturing planning data. Furthermore, several visual techniques for representing the user activity from the log files are presented which aid the identification of signature patterns relating to design rationale before finally drawing some conclusions.

\subsection{Using Immersive Virtual Reality in Engineering Applications}

VR itself takes many forms with a wide array of technologies classified as being virtual environments (VEs) in one form or another. There are now many applications where VR has being used in engineering products using a wide variety of technology [17]. This paper focuses on the HMD, where the user is surrounded by a virtual world generated by computer graphics; the models within this can be interacted with in real time (Figure 1).

In the area of product design, VR systems can change the way in which engineers develop products and work together to generate ideas, embody concepts and produce the information necessary for cost-effective manufacture; this is particularly demonstrated in Jayaram et al [17] and Ritchie et al [27]. 


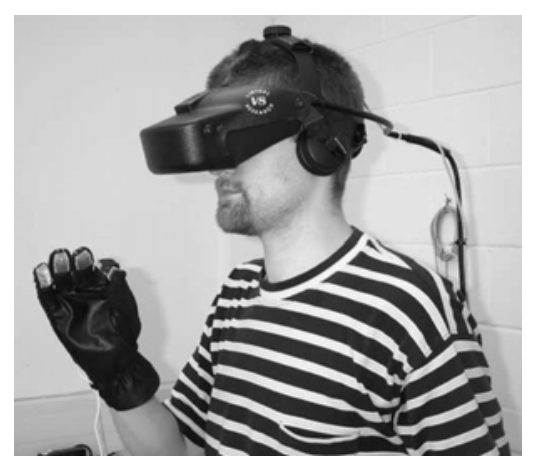

Figure 1. Head-mounted display (HMD)

\subsection{User Logging and Design Intent Identification}

Considering the designer's thinking highlights the importance of cognitive issues associated with design as a creative process. Design is described by McPhee as a mysterious mix of science and art that can only be understood by first understanding how humans think and behave [19]. He suggests it is instinctive as does Schöns's "knowing-in-action" theory [29]. Where instinctive activity does not lead to a satisfactory outcome, the designer suffers a "breakdown"; a difficulty that makes tacit reasoning more explicit [13]. Studies also repeatedly show individual's design approaches as unsystematic and ad hoc despite the influence of an explicit rationalistic guiding procedure [6]. Even when using the same methods designers produce appreciably different designs [1] and their behaviour may be as a consequence their cognitive load [12]; thus, the related notion of "modal shifts" also emerges [2]. Potentially immersive VR of the kind used in this research provides the potential for the non-intrusive analysis of design tasks and the recognition associated patterns of behaviour in a number of contexts which would be difficult with CAD. This is further amplified in downstream manufacturing planning task extraction.

The capability of VR for design tasks was demonstrated by COVIRDS (COnceptual VIRtual Design System) which showed the interactive capabilities of immersive virtual design [7]. Varga et al. [30] have also investigated the use of hand motion as a means of creating conceptualised geometry for design purposes and suggest a novel classification scheme for categorising these motions. Holt et al [14] also showed that immersive VR has an important role to play in the design process. 
There has also been research in exploiting the user-logging data created during a VR session to enhance the design process or to aid in identifying design intent. Research by Ritchie et al [25] has investigated the use of data in log files to automate the process of generating assembly plans. Wyatt $e t$ al. [31] analysed the log files from a VR geotechnical laboratory to help create a more interactive design tool which will guide users whilst they are carrying out experiments. The research carried out by Brough et al. [3] involves logging users whilst being trained to carry out assembly tasks in a VR environment. The logged data is then utilised to generate "hints" that can be presented to the user to give guidance if required. Finally in Greenhalgh [11], users are logged whilst having a VR teleconference to help determine characteristics related to the movement of users and world transition.

As can be seen from this review, there is still a need to understand how product engineering processes can be analysed in detail when applying HMD VR technology, how these can be broken down and where the emphasis on interface and technology development should take place.

\subsection{Research Work Domain}

Cable harness design is a classic design problem and even with the application of extensive CAD-based packages available many companies still employ physical prototypes for the generation and checking of cable routes [20]. There has been considerable research in finding ways to aid or automate this processes highlighted in the literature reviews in [21], [27] and [28].

A survey of industrial companies showed that there was a need for human expert intervention to make fine adjustments and verify solutions [20]; therefore it is timely to investigate the nature of new human-driven tools to support interaction with data in this domain. Therefore, the integration of the human expert into the 'system' is crucial within VR applications by treating the operator as an integral part of the system [15]. The problems encountered during the cable harness design stage have a marked impact on the time needed for new product introductions with multiple revisions of physical prototypes being commonplace [20].

In this domain, VR's unique capability unique capability makes it a powerful tool with which to carry out detailed design and manufacturing studies and as a task cable harness design is flexible enough to allow some form of limited task variety to be built into system experiments.

Earlier work at Heriot-Watt University [21] in the area of cable harness design compared an immersive VR design environment with a number of 
CAD systems showing that VR gave productivity benefits over CAD during creative cable routing design activities. Follow-on work was aimed at understanding the degree to which various aspects of the immersive VR system were contributing to these benefits and how engineering design and planning processes could be analysed in detail as they are being carried out. This was based on the table-top metaphor shown in Figure 2, using comprehensive user-logging to non-intrusively collect detailed information relating to design solutions and assembly planning approaches used by a number of engineers. with the focus on 3D volumetric design.

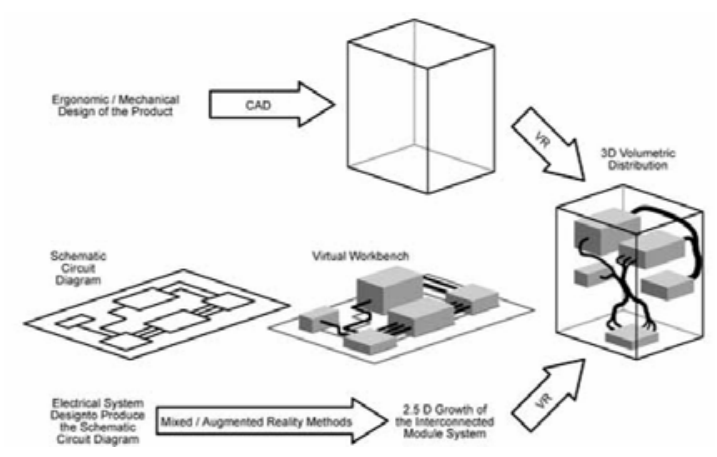

Figure 2. The workbench metaphor [15]

\section{APPARATUS AND METHODOLOGY}

\subsection{Apparatus: COSTAR Experimental Platform}

The experimental platform developed for this research was called COSTAR (Cable Organisation System Through Alternative Reality) and was implemented on an SGI ${ }^{\circledR}$ Octane ${ }^{\mathrm{TM}}$ with V12 dual head graphics driving each eye on a V8 stereo HMD. Peripherals attached to the system were a Flock of Birds ${ }^{\circledR}$ magnetic tracking system and Pinch ${ }^{\circledR}$ Gloves with system software platform being SENSE8®'s WorldToolKit ${ }^{\circledR}$ release 9.

Using COSTAR the engineer can design and assembly-plan cable harness assemblies within the immersive VR environment with all design functions being performed whilst immersed in the system (Figure 3). Interactions are achieved using a hierarchical ring menu system $[10,18]$ and 
glove pinch gestures supported by spatial input given by the Flock of Birds $^{\mathrm{TM}}$ system.

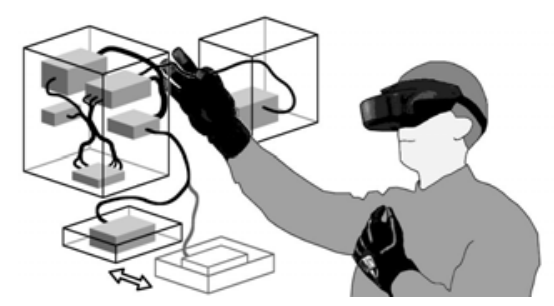

Figure 3. The COSTAR cable harness design system

An engineer inputs cable harness routes by plotting points in 3D space joined together to produce a segmented cable path. Subsequent cable editing is possible by selecting points and bending them around obstructions or bundling them. The user can also insert new points and add connectors and fasteners. Figures 5-7 show the system in use.

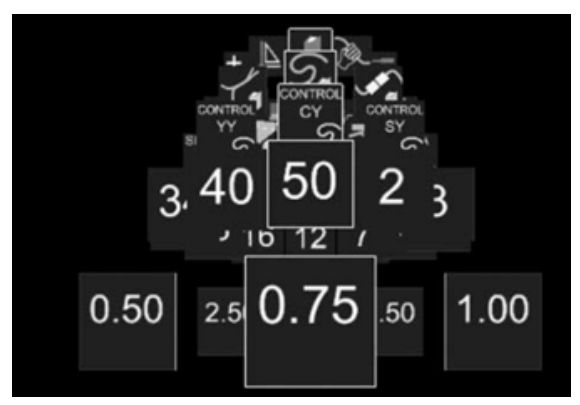

Figure 4. Hierarchical ring menu 

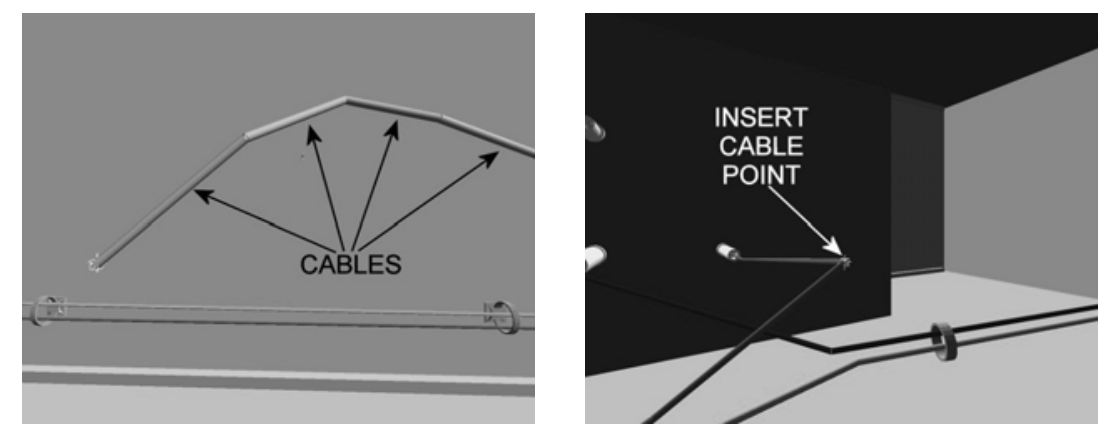

Figure 5. Creating a cable from point to point (left) and inserting a cable point (right)

As the user operates the system, COSTAR logs all of the user's cable harness design and assembly activity-related actions.

\section{EXPERIMENTAL PROCEDURE}

Three constrained design tasks were developed and implemented to evaluate each designer's time on the system. These covered common harness design activities such as routing, bundling, cable modification and choosing connectors. The log files were subsequently analysed to identify which areas of the virtual design system were used, the type of activity performed and their distribution within the total design time. The participants were given sufficient information about the goals of the task along with the main boundary conditions but were given the freedom to determine the final design solution. This task uncertainty prevented the evaluation process being a prescriptive controlled experiment which gave the participants the feel of doing a real cable harness design task using a realistic product model (Figure 6) and involved cable harness design tasks: Task 1 - outline design; Task 2 detailed design; and Task 3 - redesign. Tasks 1 and 2 were used for training and familiarisation and Task 3 for design task analysis.

Task 1: Outline Design - The user had to generate two new electrical interconnections within the product model using specific connectors and a specified cable type.

Task 2: Detailed Design - Using pre-defined cable interconnections in a model, a number of which had already been routed through a sequence of cable clips the user had to, "route the outline cables in the model through the cable clips to complete the cable harness design.” Engineering judgement 
had to be used regarding what the harness design solution was and how it was achieved. Figure 7 shows a partially completed route

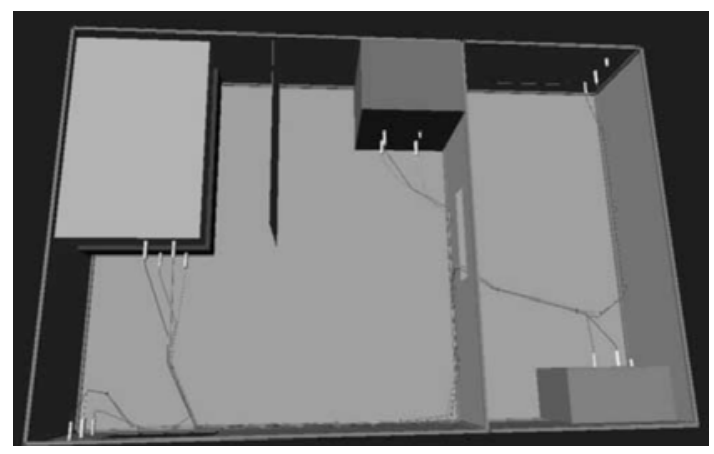

Figure 6. Model on completion of the experimental tasks

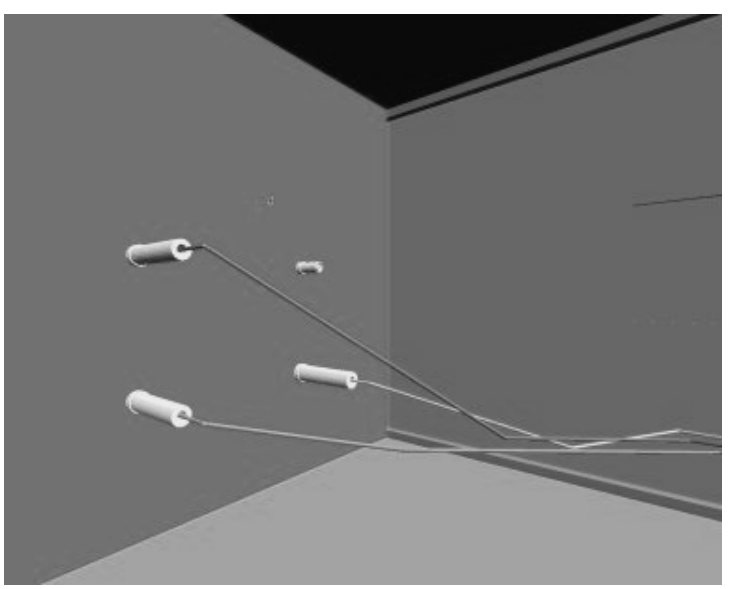

Figure 7. A partially completed route

Task 3: Redesign - The key experimental design evaluation task, this began with a product model containing a completed, fully designed harness assembly. The user had to complete some 'engineering change requests' requiring redesign of the cable harness. The specific changes required were the addition of a new cable and the removal of one and its associated connectors. Finally, there was another 'undefined' error within the model - a 
cable routed through a solid wall - which the participants were required to locate and fix by rerouting.

Ten engineers completed the experiments, all of whom were male, eight were $20-29$ years of age and two were $30-39$ years of age, all with normal or corrected-to-normal vision. Everyone was right-hand dominant with eight being right eye and two being left-eye dominant. Seven of the participants estimated that they had between 10 - 100 hours of previous CAD experience with three estimating 100-1,000 hours experience. Seven also had no prior VR experience, two had less than 10 hours and one had 100-1,000 hours of VR exposure. The design activity was followed by a semi-structured interview during which feedback was collected.

\section{ANALYSIS OF RESULTS}

Data collected via log files included performance and usage data. In addition, post-experiment data was collected in the form of system usability and functionality data through structured questionnaires [27], along with informal subjective discussions. From Task 3, the system usage was analysed using novel design and system state categories developed specifically for these experiments, following on from less detailed categories applied by Chi Chen et al. [4] in their experiments.

Environmental categories were developed from which, on analysing the $\log$ files, produced the distribution shown in Table 1 and Figure 8. From these the average percentage of time spent in each of the new environmental category subdivisions were as follows: 69\% involved users carrying out activities within the model and being creative; only $8 \%$ was spent in 'help/task instruction' supporting the informal feedback from the users that the system was easy and intuitive to use and $23 \%$ of the time interacting with the menus.

Table 1: Environmental category subdivisions for design task 3

\begin{tabular}{|c|c|c|c|c|c|}
\cline { 2 - 6 } \multicolumn{1}{c|}{} & \multicolumn{5}{c|}{ Environmental Categories } \\
\cline { 2 - 6 } & Model & Help/Task Instruction & $\begin{array}{c}\text { Menu (No } \\
\text { model } \\
\text { visible) }\end{array}$ & $\begin{array}{c}\text { Menu (model } \\
\text { visible) }\end{array}$ & Total \\
\hline Mean Time (s) & 867 & 101 & 289 & 0 & 1257 \\
\hline$\%$ & $69 \%$ & $8 \%$ & $23 \%$ & $0 \%$ & $100 \%$ \\
\hline
\end{tabular}




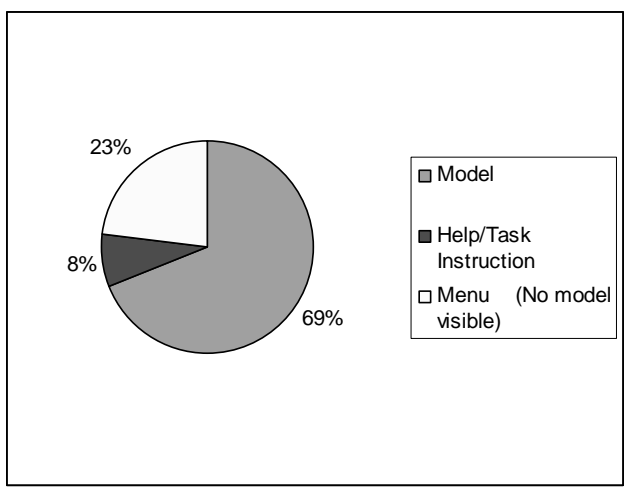

Figure 8. Average time distribution for environmental category subdivisions

After analysing the data and design process activities, action sequences within the log files were grouped together to enable an analysis of the design tasks carried out by the users. From these "task plans" [22] a set of design activity categories were defined so that participant activities could be compared and correlated between each other and the environmental categories shown in Table 1, these activity categories were:

(a) Design: activity the user carries out to directly amend the design solution or associated documentation.

(b) Information: user activity which involves acquiring information from a text screen.

(c) System Operation: activities required to operate the system but do not affect the solution.

(d) Navigation: all activity which modifies the participant's viewpoint but does not normally change the solution.

Since design is at the heart of the study then this was further subdivided into three further categories to enable more detailed analysis of the design process:

(a) Design - Goal: user actions which alter the design solution/model and advance the design towards its final state.

(b) Design - Support: activities which enable the user to subsequently alter the design.

(c) Drag \& Drop (Position Edit): the movement and amendment of an object by the user interactively within the model environment.

The results from the activity category analysis are shown together with more detail on the subsequent statistical analysis in Table 2 and Figure 10 from [27]. 
From these it can be seen that for an average of $41 \%$ of the time users were navigating around the model; which was due to the fact that the model itself was presented in large scale where it surrounded the engineer. Flying was employed for navigation since this was the usual means using an HMD. With the speed kept constant to reduce confounding variables in experimentation. However, the categorisation picked this up as a major disadvantage in the system as did subsequent interviewing of participants. Therefore, it would be advantageous to reduce navigation time which backed up an important finding from Ng [21] where in his application user scaling of the virtual model speeded up navigation, considerably enhanced the designer's experience and perception of the product model and improved the overall productivity of the design task.

Around 27\% of the designer's average time within the system was spent on design-related tasks. It was apparent from the results that the menu and navigation interfaces could be improved to free up more time for creative design.

Furthermore, it was important to understand how much time was being spent by designers in unproductive activities; therefore, two supplementary categories which were applicable across all of the existing design categories, i.e.:

(a) Unproductive Activity: all category activity that does not affect the final outcome of a task.

(b) Sequence Breaks: pauses in activity between the end of one action sequence and another, e.g. thinking time, rest time or activities that do not register as interactions such as head or hand movements.

The results of these further subdivisions are shown below in Table 2.

Table 2: Supplementary category subdivisions

\begin{tabular}{|c|c|c|}
\cline { 2 - 3 } \multicolumn{1}{c|}{} & \multicolumn{2}{c|}{ Activity Category } \\
\cline { 2 - 3 } \multicolumn{1}{c|}{} & Unproductive Activity & Sequence Breaks \\
\hline Mean Time (s) & 70 & 356 \\
\hline St.Dev. & 51 & 110 \\
\hline Mean Time(\%) & 6 & 28 \\
\hline
\end{tabular}

These data show that on average for around $28 \%$ of the time there are large parts of the process during where users are taking breaks from carrying out any form of activity. Due to the fact that these task durations are individually so short and unlikely to be related to resting then it is hypothesised that these could be associated "thinking time" where the designer could be considering options about menu interfacing, design, design modifications, etc. These issues will require further investigation; however, 
this analysis shows the design categorisation scheme developed in this research and the capability to monitor and log user movements to isolate events in this way could provide a means of non-intrusively analysing engineering intent; the holy grail of engineering task analysis..

Another major result is the ability to investigate statistically the cause and effect relationships between the various categories and subcategories. Consequently, statistical tests were carried out to see if any significant relationships could be identified between these. This analysis compared all of the environmental categories and activity categories together and is presented in detail in [27]. The results illustrate some obvious and not-soobvious cause and effect relationships between the various activity and environment categories used for the cable harness design process and give a novel insight into the design process itself and the functionality of the COSTAR immersive VR design system as a tool.

\section{CABLE HARNESS ASSEMBLY AND CABLE HARNESS INSTALLATION PLANNING}

One major benefit of CAD is the generation of downstream manufacturing information; indeed, the integration of design and manufacturing in this way seems to have been forgotten about in most researched VR applications. However, for a realistic means of carrying out assembly planning there is a considerable need for direct user input in a fashion that supports natural assembly processes. Immersive VR of the type used in this research provides this opportunity. Within traditional CAD system interfaces there are considerable interruptions to the assembly planner's creative thought processes whilst they generate assembly sequences and this can of course affect the quality of the assembly plan output. A more intuitive method of generating plans is required in which the user can describe their assembly activities ergonomically; not necessarily copying but mimicking assembly build requirements through actions and demonstrations of processes rather than having to explicitly describe them and visualise these processes in their minds and translate them into some form of formal assembly document. Within this research it is felt that immersive VR has an particularly important role to play. Therefore, it was decided to investigate the possibility of automatically generating usable cable harness assembly plans using the immersive VR interface by allowing the manufacturing planner to intuitively explore the equipment assembly (Figure 6) and then: (1) choose connector positions within the bulkheads to 
mimic bulkhead connector installation; (2) explore and select cable harness and associated connector geometries to demonstrate a cable harness assembly process planning; and (3) to follow this up by indicating the cable and bulkhead connector attachments to emulate the installation of the final cable harness in the virtual model. Whilst carrying this out, the user is again fully and non-intrusively monitored and data logged. From these logged data, the automatic parsing of the associated files and analysis of the data syntax allows the translation of the standard syntax into associated standard English instructions. This automatically generates an installation assembly plan from the data which requires no interactive creation of instructions or subsequent amendments from the user.

This approach supports the work carried out by Ritchie et al. [24] which showed that production of usable assembly plans via an immersive VR interface. However, work by Dewar et al. [8] showed that virtual assembly times were very different from real world times. To overcome this, the COSTAR assembly system was extended to cross refer real world assembly times onto identifiably logged virtual equivalent tasks using the same parsed file syntax identification approach. Tables of standard assembly times for fitting bulkhead connectors in place, fitting connectors to harness wires or bindles and fitting harness connectors into bulkhead connectors were tabulated from real world method studies and applied to the equivalent virtual tasks. The non-intrusive logging of the planner enabled the development and generation of production-readable assembly plans without the need for human intervention; a major benefit over CAD methods. Also harness access and plan feasibility could be checked ergonomically.

The interface for assembly planning is shown in Figure 9 and the assembly plans automatically generated for bulkhead connector installation, harness assembly and harness installation, along with the corresponding realworld assembly times for each operation, are shown in Figure 10.

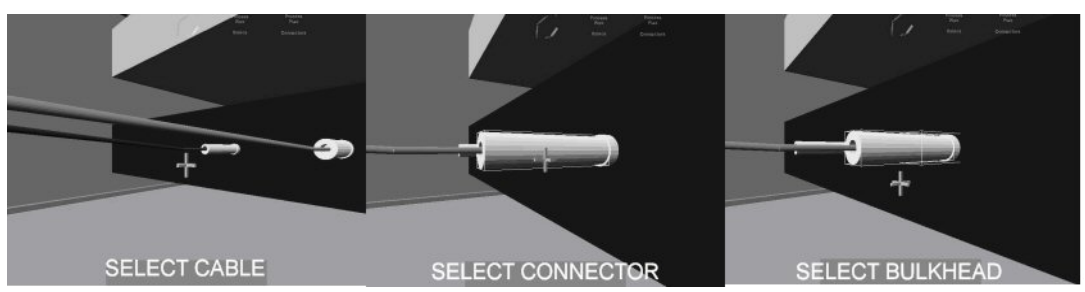

Figure 9. VR user interface for assembly planning 
BULKHEAD CONNECTOR INSTALL SEQUENCE

\begin{tabular}{|c|c|c|c|c|}
\hline Op Num & W/Centre & Assembly Instructions & Tooling & $\begin{array}{l}\text { Assembly } \\
\text { Time (s) }\end{array}$ \\
\hline 10 & Cable Bench & $\begin{array}{l}\text { Connect bulkhead connector CON01 (Type: plug } \\
\text { Shell size: } 1 \text { Number of poles: } 2) \text { to bulkhead } \\
3250 \text { located at position }(3250,-500,3725) \text { and } \\
\text { Orientation }(0,-0,0.707107,0.707107)\end{array}$ & $\begin{array}{l}\text { Hand } \\
\text { Assembly }\end{array}$ & 7.8 \\
\hline 20 & Cable Bench & $\begin{array}{l}\text { Connect bulkhead connector CON04 (Type: } \\
\text { socket Shell size: } 1 \text { Number of poles: 2) to } \\
\text { bulkhead } 2250 \text { located at position }(2250,-500,325) \\
\text { and Orientation }(-0,-1,-0,4.37114 \mathrm{e}-08)\end{array}$ & $\begin{array}{l}\text { Hand } \\
\text { Assembly }\end{array}$ & 19.9 \\
\hline 30 & Cable Bench & $\begin{array}{l}\text { Connect bulkhead connector CON05 (Type: } \\
\text { socket Shell size: } 2 \text { Number of poles: } 7) \text { to } \\
\text { bulkhead } 1750 \text { located at position }(1750,-500,325) \\
\text { and Orientation }(-0,-1,-0,4.37114 \mathrm{e}-08)\end{array}$ & $\begin{array}{l}\text { Hand } \\
\text { Assembly }\end{array}$ & 17.7 \\
\hline 40 & Cable Bench & $\begin{array}{l}\text { Connect bulkhead connector CON10 (Type: plug } \\
\text { Shell size: } 2 \text { Number of poles: } 7) \text { to bulkhead - } \\
2250 \text { located at position }(-2250,-500,-2175) \text { and } \\
\text { Orientation }(-0,-1,-0,4.37114 \mathrm{e}-08)\end{array}$ & $\begin{array}{l}\text { Hand } \\
\text { Assembly }\end{array}$ & 29.6 \\
\hline
\end{tabular}

Figure 10(a)

CABLE HARNESS BUILDING SEQUENCE

\begin{tabular}{|l|l|l|l|l|}
\hline Op Num & W/Centre & Assembly Instructions & Tooling & $\begin{array}{l}\text { Assembly } \\
\text { Time (s) }\end{array}$ \\
\hline 10 & Cable Bench & $\begin{array}{l}\text { Connect cable CAB02(Type: CONTROLCY } \\
\text { Number of Cores: 7 Core Cross-Section: 1 Colour } \\
\text { (RGB): 225,125,0) to inline connector CON23 } \\
\text { (Type: plug Shell size: 2 Number of poles: 7) }\end{array}$ & $\begin{array}{l}\text { Hand } \\
\text { Assembly }\end{array}$ & 8.2 \\
\hline 20 & Cable Bench & $\begin{array}{l}\text { and inline connector CON24 (Type: socket Shell } \\
\text { size: 2 Number of poles: 7) }\end{array}$ & $\begin{array}{l}\text { Hand } \\
\text { Assembly }\end{array}$ & 22.6 \\
\hline 30 & $\begin{array}{l}\text { Connect cable CAB01 (Type: SINGLECORE } \\
\text { Number of Cores: 1 Core Cross-Section: 4.8 } \\
\text { Colour (RGB): 255,0,0) to inline connector } \\
\text { CON22 (Type: plug Shell size: 1 Number of poles: } \\
\text { 2) }\end{array}$ & $\begin{array}{l}\text { Hand } \\
\text { Assembly }\end{array}$ & 7.6 \\
\hline 40 & Cable Bench Bench & $\begin{array}{l}\text { and inline connector CON21 (Type: socket Shell } \\
\text { size: 1 Number of poles: 2) }\end{array}$ & $\begin{array}{l}\text { Hand } \\
\text { Assembly }\end{array}$ & 20.7 \\
\hline
\end{tabular}

Figure 10(b) 
INSTALL CABLE HARNESS ASSEMBLY INTO EQUIPMENT

\begin{tabular}{|c|c|c|c|c|}
\hline Op Num & W/Centre & Assembly Instruction & Tooling & $\begin{array}{l}\text { Assembly } \\
\text { Time (s) }\end{array}$ \\
\hline 10 & Assy Station & $\begin{array}{l}\text { Connect inline connector CON21 (Type: socket } \\
\text { Shell size: } 1 \text { Number of poles: 2) to bulkhead } \\
\text { connector CON01 (Type: plug Shell size: } 1 \\
\text { Number of poles: 2) located at position }(3250,- \\
500,3725) \quad \text { and Orientation } \\
0,0.707107,0.707107)\end{array}$ & $\begin{array}{l}\text { Hand } \\
\text { Assembly }\end{array}$ & 5.7 \\
\hline 20 & Assy Station & $\begin{array}{l}\text { Connect inline connector CON22 (Type: plug } \\
\text { Shell size: } 1 \text { Number of poles: 2) to bulkhead } \\
\text { connector CON04 (Type: socket Shell size: } 1 \\
\text { Number of poles: } 2 \text { ) located at position }(2250,- \\
500,325) \text { and Orientation }(-0,-1,-0,4.37114 \mathrm{e}-08)\end{array}$ & $\begin{array}{l}\text { Hand } \\
\text { Assembly }\end{array}$ & 14.8 \\
\hline 30 & Assy Station & $\begin{array}{l}\text { Connect inline connector CON23 (Type: plug } \\
\text { Shell size: } 2 \text { Number of poles: } 7 \text { ) to bulkhead } \\
\text { connector CON05 (Type: socket Shell size: } 2 \\
\text { Number of poles: } 7 \text { ) located at position }(1750,- \\
500,325) \text { and Orientation }(-0,-1,-0,4.37114 \mathrm{e}-08)\end{array}$ & $\begin{array}{l}\text { Hand } \\
\text { Assembly }\end{array}$ & 9.1 \\
\hline 40 & Assy Station & $\begin{array}{l}\text { Connect inline connector CON24 (Type: socket } \\
\text { Shell size: } 2 \text { Number of poles: } 7 \text { ) to bulkhead } \\
\text { connector CON10 (Type: plug Shell size: } 2 \\
\text { Number of poles: } 7 \text { ) located at position }(-2250,- \\
500,-2175) \text { and Orientation }(-0,-1,-0,4.37114 \mathrm{e}- \\
08)\end{array}$ & $\begin{array}{l}\text { Hand } \\
\text { Assembly }\end{array}$ & 70.7 \\
\hline
\end{tabular}

Figure 10(c)

STANDARD REAL WORLD ASSEMBLY TIMES FOR EACH COMPONENT

\begin{tabular}{|c|c|c|c|}
\hline Component & Assembly Time (s) & Component & Assembly \\
\hline CAB01 & 7.592 & CON22 & 22.36 \\
\hline САB02 & 8.233 & CON23 & 17.36 \\
\hline CON01 & 13.56 & CON24 & 93.27 \\
\hline CON04 & 34.63 & ВН-2250 & 29.63 \\
\hline CON05 & 26.83 & BH1750 & 17.70 \\
\hline CON10 & 100.3 & BH2250 & 19.87 \\
\hline CON21 & 26.40 & BH3250 & 7.844 \\
\hline
\end{tabular}

Figure10(d)

Figure10. Assembly plans generated from assembly planner logging

These outputs show that real world plans and associated real-world operation times can be generated automatically from user interaction within immersive VR design and planning systems. This matching of real world times with the virtual-equivalent activities demonstrates wider and more profound opportunities, such as how interactive systems of this kind could be used in generic project planning domains by carrying out interactive assembly/disassembly in exactly this way [9] for applications such as project planning as well as demonstrating the potential for outputting structured data 
the subsequent analysis of which could form the basis for formalizing manufacturing intent.

\section{AUTOMATED LOG FILE ANALYSIS AND PROCESS PLAN GENERATION}

Previously, the log files generated during the VR design sessions were all manually categorised and analysed which proved to be very time consuming. To reduce the analysis time required, a system was developed to automatically parse the log files and then apply an action category to each user action sequence recorded. One such log file is shown in Figure 11 and, as can be seen, a timestamp is also attached to each record. This gives a chronological history of the activities carried out within the virtual environment as the user's design solution evolved. Further parsing of this file via a spreadsheet macro and subsequent automatic classification into the various design activity categories mentioned previously enabled the automatic generation of a process flow map of the design engineering process for Task 3 of the cable harness design activity; the first time this has been possible for a realistic design task..

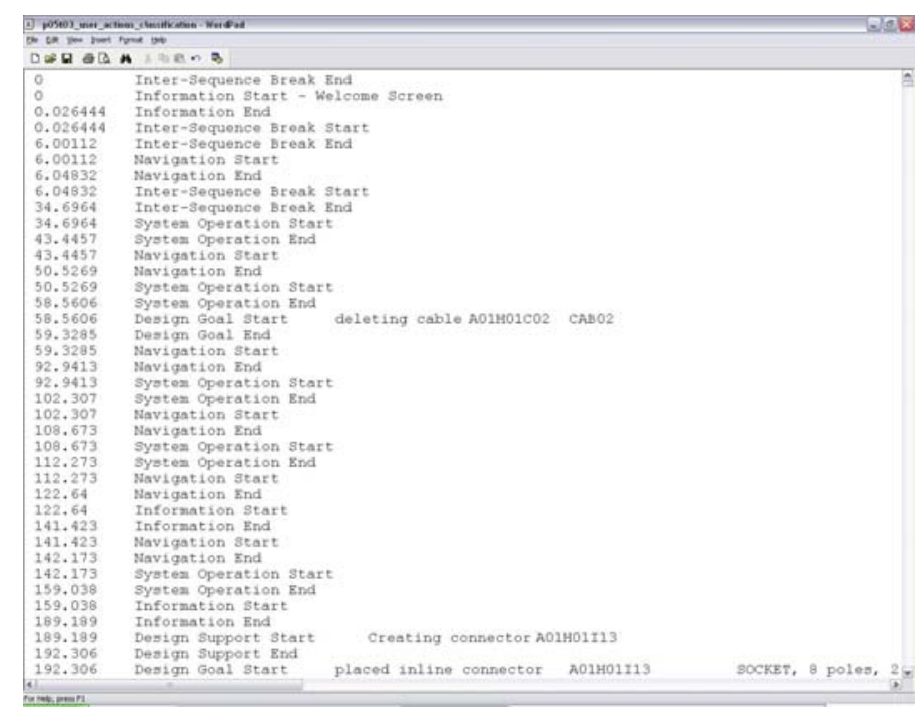

Figure 11. Activity category generation 


\begin{tabular}{|c|c|c|c|}
\hline Therblig & Symbol & Therblig & Symbol \\
\hline SEARCH & & USE & \\
\hline FIND & & DISASSEMBLE & \\
\hline SELECT & & INSPECT & \\
\hline GRASP & & PRE-POSITION & \\
\hline HOLD & & $\begin{array}{l}\text { RELEASE } \\
\text { LOAD }\end{array}$ & \\
\hline $\begin{array}{l}\text { TRANSPORT } \\
\text { LOADED }\end{array}$ & & $\begin{array}{l}\text { UNAVOIDABLE } \\
\text { DELAY }\end{array}$ & \\
\hline $\begin{array}{l}\text { TRANSPORT } \\
\text { EMPTY }\end{array}$ & & $\begin{array}{l}\text { AVOIDABLE } \\
\text { DELAY }\end{array}$ & \\
\hline POSITION & & PLAN & \\
\hline ASSEMBLE & & REST & \\
\hline
\end{tabular}

Due to the nature of the interface developed for this immersive virtual design environment, it was observed that many of the ergonomically associated motions, movements and activities carried out whilst navigating interfacing with the model and menus and creating and amending the geometry appeared to mimic assembly movements and tasks. As a consequence of this it was decided to see if there were any tools that existed 
to enable the analysis of assembly tasks which could be used to analyse 3D and - particularly VR - interfaces of the kind developed for this research. The obvious candidate for this was the use of Gilbreth's therbligs $[23,16]$. Therbligs, invented by Frank Gilbreth, consists of a library of symbols that represent all the mental and physical processes that occur during an assembly task; these are summarised in Figure 12.

After studying these in detail and mapping them onto relevant parsed sections of the log files it was possible to automatically generate the relevant therbligs associated with the ergonomic interactions and thought processes carried out by the engineer as they progressed through the design activity. As a consequence of this, the relevant chronological series of therbligs were then mapped against the appropriate design activity categories on the flow diagram (Figure 13). By marrying up the therblig descriptions in Figure 12 with the relevant lines on the process flow map in Figure 13, the activities of the designer can be observed in more detail. For example, in line 2 of the process diagram (highlighted) it can be seen during this part of the 'Design Drag and Drop Start' the engineer is searching for and then finding the cable to be moved. Next, the cable is selected, grasped, held and then transported to a different location. Finally the cable is positioned in the correct position and released. Similar therbligs can also be generated for other assembly approaches [31].

Therefore, visualising the therblig symbols allows a quick and detailed understanding of design activities in a way simply not possible before as well as identifying potential routes for inefficiencies in the process, identifying patterns of repeated design behaviour and any inefficiency in the design interaction process. One of the biggest advantages of this approach is that it can be done automatically; potentially in real time. It also enables a quick visual analysis to be carried out to identify patterns of behaviour during design and manufacturing activities. Similar sets of therbligs may point to regular behaviours which can be embedded in ontologies, standardised methods or other means of defining processes or means of operating. 


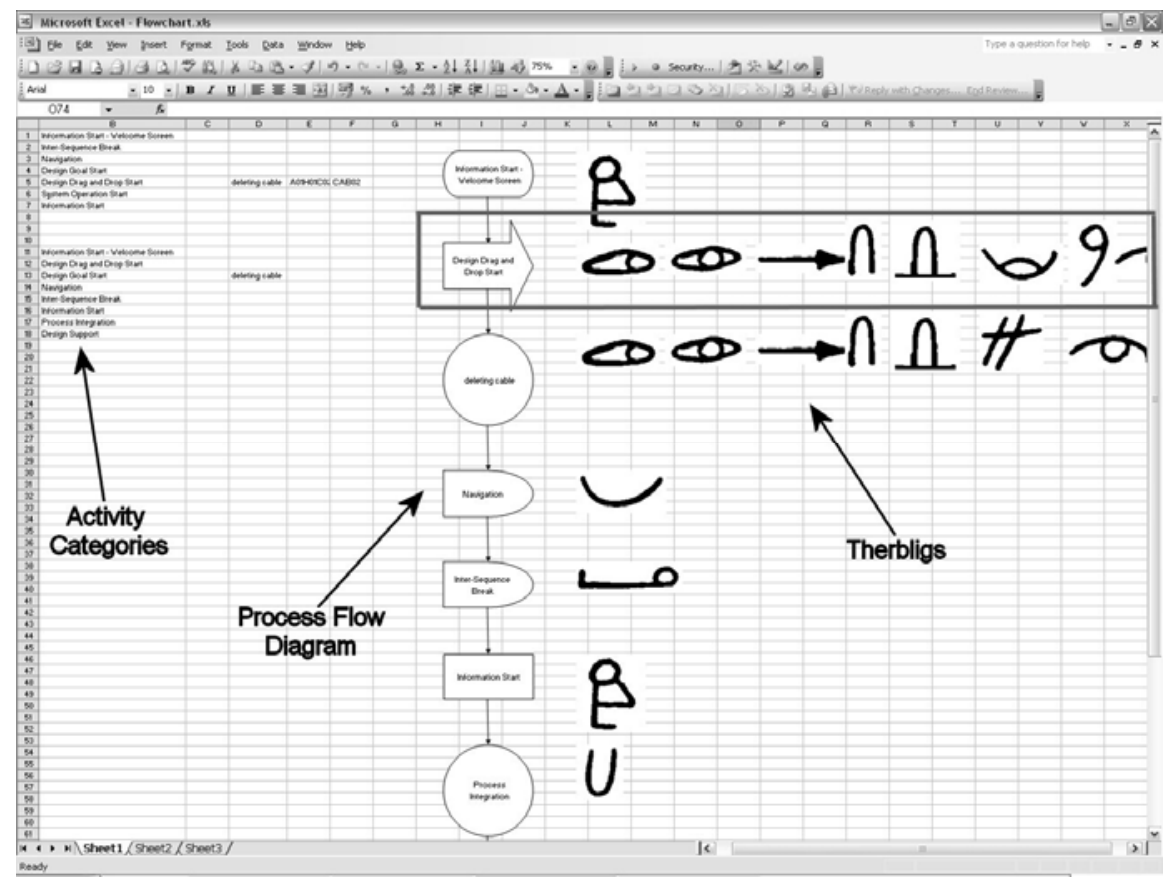

Figure 13 Process flow diagram and therbligs

Another Gilbreth creation developed to study motion during assembly processes and adopted in this research to investigate design interaction in 3D environments is the use of the chronocyclegraph [23]. Traditionally, this involved attaching a light source, flashing at a known constant frequency, to a person's hand while carrying out a task. This process is recorded over a period of time using one long-exposure photograph which showed the motion of the person's hand during the assembly task. From the path traces of the user's hands, called chronocyclegraphs, regions of unnecessary motion and activity, and therefore inefficiency, are highlighted and allow the optimisation of the task. 3D wire frame chronocyclegraphs could also be produced to facilitate motion planning. The flashing of the light source and positions of the bulbs during exposure also allow velocities and accelerations to be calculated if required. Using the HMD and hand motion tracking data recorded in the log files generated in the VR experiments these data are already being recorded and allows a chronocyclegraph to be automatically created as shown in Figure 14. This figure shows the path that the left-hand takes during a design session with the colours of the path corresponding to a particular activity category as defined earlier in this paper. Since a 
timestamp is attached to each user action, the velocity and acceleration of the user's motion can be calculated, in a similar fashion to the original chronocyclegraphs. One potential use of the velocity and acceleration information would be to gauge the designer's confidence level based on the speed of movement and level of deviation in the direction of travel. Furthermore, therbligs can also be mapped onto positional information linking the detailed design and user interface task analysis classification with the design categorisation. In addition, this will provide an ability to "replay" a previous design activity and would also allow a design to be "rolled back" to a specific point to let the designer to work on it again.

The work carried out in this research and the associated paper by Lim et al [26] is the first time that Gilbreth's methods have been combined in this way to analyse virtual tasks of the kind.

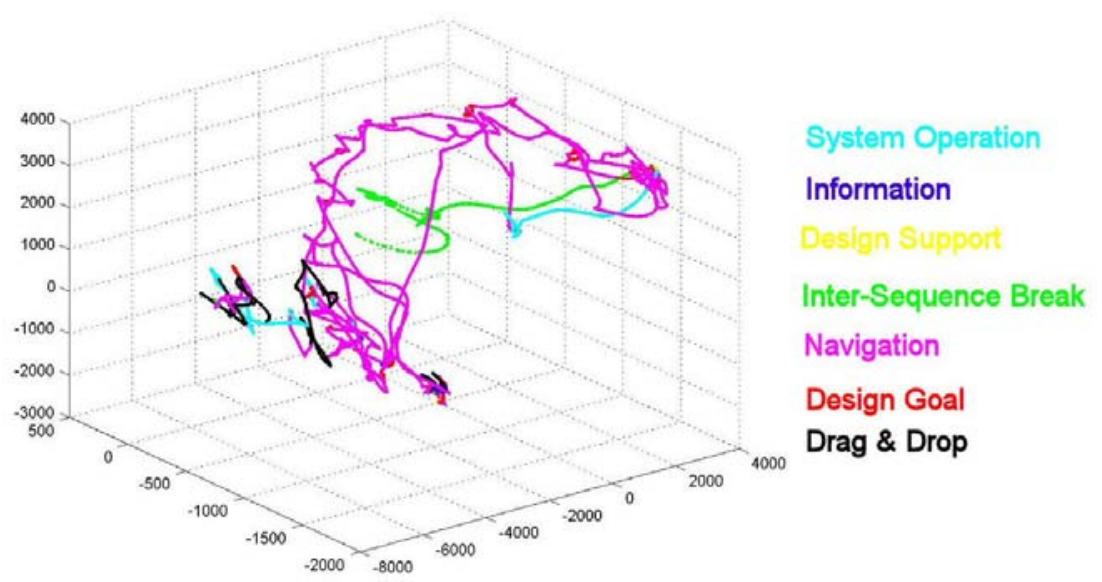

Figure 14. Left Hand Motion Path

It is envisaged that further analysis of this output will aid in the identification of design intent and knowledge acquisition.

\section{CONCLUSIONS}

A number of novel outputs from this research have demonstrated the potential for immersive VR in aiding the analysis of and supporting product engineering tasks. 
It is possible to design and automatically plan the assembly and installation of cable harness assemblies in immersive virtual environments using HMDs.

It is also possible to examine, categorise and measure the wide range of design activities carried out by cable harness design engineers; something which has not been done to this level in the past. Design processes can be analysed in detail through a novel means of categorisation so that system and user information can be investigated with regard to process improvement. As a consequence, design processes can also be automatically mapped from user logging data. This categorisation scheme will be applied to CAD-related tasks in the near future so that these can be compared with VR-based CAD systems.

Assembly planning can be greatly enhanced by automatically generating these from user logging data, parsing accordingly and outputting readable planning instructions. Estimates of real world assembly times can also be calculated after virtual activities are mapped from the log files onto real world equivalents.

Therbligs have been applied to a 3D interface to enable a detailed understanding of designer interactions and process activities. These have also been combined with process maps to enable the visual analysis of design activities Chronocyclegraphs have also been produced, enabling - for the first time - a detailed study of 3D virtual interfaces as well as design processes when combined with activity categorisation information.

One area where all of these data will prove useful is that 'thinking time' could be extracted from the categorisation, therbligs and chronocyclegraph information, e.g looking for pauses in activity or changes in physical behaviour, which may point to areas where the user is thinking about the design providing a possibility to imply design intent or reasoning from actions leading up to and after a decision-making event.

For cable harness routing, VR can give productivity gains over CAD [14]; however, a more detailed investigation of cable harness design activities will be necessary to determine which tasks are best suited to VR and which are best suited to CAD. The design categorisation developed and successfully tested as part of this research, is central to such an investigation.

Areas for interface improvement have been identified using all of these tools from these experiments for improving navigation and menu design, although they are not reported in detail in this paper. Once improvements have been implemented, the affects of these changes to the system's usability and functionality can be measured against the benchmarks reported here by reusing the categorisation scheme. 
Next, assembly planning sequences along with the novel application of associated real-world assembly times can be generated by non-intrusively monitoring and logging the user. This logged data has also been utilised to automate the process of activity categorisation, creating process flow diagrams and motion study analysis. From this study, improvements in assembly planning interface design are being planned to make the assembly and disassembly of cable harnesses more realistic. In addition, it is proposed that log file analysis can aid the acquisition of design knowledge.

\section{Acknowledgements}

We would like to acknowledge funding of this work by the UK Engineering and Physical Sciences Research Council Innovative Manufacturing Research Centre at Heriot-Watt University (The Scottish Manufacturing Institute) as well as the numerous industrial partners involved in the project.

\section{References}

1. Adelson B, Solway E (1985) The Role of Domain Experience in Software Design. IEEE Transactions on Software Engineering 11:1351-1360.

2. Akin Ö, Lin C (1995) Design Protocol Data and Novel Design Decisions. Design Studies, 16(2), pp.211-236.

3. Brough JE, Schwartz M, Gupta SK, Anand DK (2006) Towards the development of a virtual environment-based training system for mechanical assembly operations”, Proceedings of the $1^{\text {st }}$ International Virtual Manufacturing Workshop (25-29 March), Virginia, USA, pp 11-15.

4. ChiCheng C, Jianzhong M, Gadh, R. (2002) A Quantitative Analysis on Virtual Reality-Based Computer Aided Design System Interfaces. Computing and Information Science in Engineering, 2:216-223.

5. Conru AB. (1993) Computational Support for Interactive Cable Harness Routing and Design. In: 19th Annual ASME Design Automation Conference, pp 551-558.

6. Cross N (2001) Design cognition: Results from protocol and other empirical studies of design activity, In C. Eastman, M. McCracken \& W. Newstetter (eds.), Design knowing and Learning: Cognition in Design Education. Amsterdam: Elsevier, pp 79-103.

7. Dani TH, Gadh R (1997) Creation of Concept Shape Design via a Virtual Reality Interface, Computer-Aided Design, 29 (8):555-563.

8. Dewar RG, Ritchie JM, Carpenter I D, Simmons JEL (1997) Tools for Assembly in a Virtual Environment, In: Proceedings of ICMA '97, University of Hong Kong, pp 583-587.

9. Gardiner PD, Ritchie JM (1999) Project Planning in a Virtual World: Information Management Metamorphosis or Technology Going Too Far, Information 
Management 19(6):485-494.

10. Gerber D, Bechmann D (2004) Design and Valuation of the Ring Menu in Virtual Environments. In: Immersive Projection Technologies IPT 2004, Ames, Iowa, USA.

11. Greenhalgh C (1997) Analysing movement and world transitions in virtual reality tele-conferencing, $5^{\text {th }}$ European Conference on Computer Supported Cooperative Work (7-11 September), Lancaster, UK.

12. Guindon R (1990) Designing the design process: Exploiting opportunistic thoughts, Human-Computer Interaction 5(2), pp.305-344.

13. Guindon R, Krasner H, Curtis B (1987): Breakdowns and Processes During the Early Activities of Software Design by Professionals. Empirical Studies of Programmers - Second Workshop (December) Washington, DC, pp 65-82.

14. Holt POB, Ritchie JM, Day PN (2004) Immersive Virtual Reality in Manufacturing: Design Metaphors and Cognitive Ergonomics. Computing and Information Science in Engineering 4(3):161-170.

15. Holt POB, Russell GT (1999) Psychology as a Science of Design in Engineering. Proceedings of the British Psychological Society 7(2):115.

16. http://gilbrethnetwork.tripod.com/therbligs.html Therblig

17. Jayaram S, Vance J, Gadh R, Jayaram U, Srinivasan H (2001) Assessment of VR Technology and its Application to Engineering Problems, Computing and Information Science in Engineering 1:72-83.

18. Liang J, Green M. (1994) JDCAD: A Highly Interactive 3D Modeling System. Computers and Graphics (ACM) 18(4):499-506.

19. McPhee K (1997) Design Theory and Software Design, Technical Report TR 9626, Department of Computer Science, University of Alberta, Canada.

20. Ng FM, Ritchie JM, Simmons JEL, Dewar RG (2000) Designing Cable Harness Assemblies in Virtual Environments. Materials Processing Technology 107:37-43.

21. Ng FM. (1999) Virtual Reality and Computer-Based Tools for the Routing of Cable Harnesses. PhD Thesis, Heriot-Watt University, Edinburgh.

22. Preece J, Rogers Y, Sharp H, Benyon D, Holland S, Carey T (1994), HumanComputer Interaction, Addison-Wesley, Wokingham, England.

23. Price B (1989) Frank and Lillian Gilbreth and the manufacture and marketing of motion study, 1908-1924, Business and Economic History, Second series, 18:88-98.

24. Ritchie JM, Dewar RD, Simmons JEL (1999) The Generation and Practical Use of Plans for Manual Assembly using Immersive Virtual Reality, Engineering Manufacture, Institution of Mechanical Engineers, Part B 213: 461-474.

25. Ritchie JM, Dewar RG, Robinson G, Simmons JEL, Ng FM (2006) The role of nonintrusive operator logging to support the analysis and generation of product engineering data using immersive VR, Virtual and Physical Prototyping 1(2):117134 .

26. Ritchie JM, Lim T, Sung RS, Corney JR, Rea H (2007) Part B: The analysis of Design and Manufacturing Tasks using Haptic and Immersive VR - Some Case Studies, Proceedings Advanced Summer Institute ( $30^{\text {th }}$ May 2007-6 $6^{\text {th }}$ June 2007), Universtiy Transilvania Brasov, Romania.

27. Ritchie JM, Sung RCW, Robinson G, Day PN, Dewar RG, Simmons JEL (2007) Cable harness design, assembly and installation using immersive virtual reality, Virtual Reality Journal, Special Issue on Virtual Manufacturing (eds. J M Ritchie and R G Dewar - to be published summer 2007) 
28. Robinson G, Ritchie JM, Day PN, Dewar RG (2007) System design and user evaluation of Co-Star: An immersive stereoscopic system for cable harness design, Computer-Aided Design 39(4):245-257.

29. Schon DA (1991) The Reflective Practitioner: How Professionals Think in Action, Arena.

30. Varga E, Horvath I, Rusak Z, de Smit B, Broek H. (2004) Survey and Investigation of Hand Motion Processing Technologies for Compliance with Shape Conceptualisation, In: Proceedings of DETC'04 ASME Design Engineering Technical Conferences and Computers and Information in Engineering Conference; ASME, DETC2004/CIE-57710, pp 1-14.

31. Wyatt TR, Arduino P, Macari EJ (1999) Assessment of a Virtual Laboratory for Geotechnical Engineering, Proceedings. ASEE Annual Conference \& Exposition (June), Charlotte, NC 